\title{
Towards the design of new and improved drilling fluid additives using molecular dynamics simulations
}

\author{
RICHARD L. ANDERSON ${ }^{1}$, H. CHRISTOPHER GREENWELL ${ }^{1 \dagger}$, JAMES L. SUTER ${ }^{2}$, \\ REBECCA M. JARVIS ${ }^{3}$ and PETER V. COVENEY ${ }^{2}$ \\ ${ }^{1}$ Durham University, Department of Chemistry, South Road, Durham DH1 3LE, United Kingdom \\ ${ }^{2}$ Centre for Computational Science, Department of Chemistry, University College London \\ 20 Gordon Street, London WC1H 0AJ, United Kingdom \\ ${ }^{3}$ School of the Environment and Natural Resources, Bangor University \\ Gwynedd, LL57 2UW, United Kingdom
}

Manuscript received on May 22, 2008; accepted for publication on May 18, 2009

\begin{abstract}
During exploration for oil and gas, a technical drilling fluid is used to lubricate the drill bit, maintain hydrostatic pressure, transmit sensor readings, remove rock cuttings and inhibit swelling of unstable clay based reactive shale formations. Increasing environmental awareness and resulting legislation has led to the search for new, improved biodegradable drilling fluid components. In the case of additives for clay swelling inhibition, an understanding of how existing effective additives interact with clays must be gained to allow the design of improved molecules. Owing to the disordered nature and nanoscopic dimension of the interlayer pores of clay minerals, computer simulations have become an increasingly useful tool for studying clay-swelling inhibitor interactions. In this work we briefly review the history of the development of technical drilling fluids, the environmental impact of drilling fluids and the use of computer simulations to study the interactions between clay minerals and swelling inhibitors. We report on results from some recent large-scale molecular dynamics simulation studies on low molecular weight water-soluble macromolecular inhibitor molecules. The structure and interactions of poly(propylene oxide)-diamine, poly(ethylene glycol) and poly(ethylene oxide)-diacrylate inhibitor molecules with montmorillonite clay are studied.
\end{abstract}

Key words: clay swelling, drilling fluids, molecular dynamics simulation.

\section{INTRODUCTION TO DRILLING FLUIDS}

During the drilling of subterranean oil wells, technical drilling fluids comprising a range of chemicals and polymers are used to lubricate the drill bit, maintain hydrostatic pressure, suspend cuttings and transfer readings from analytical equipment back to the surface. In addition to this, the fluid contains additives to prevent the swelling of any clay shale formations (known as reactive

Selected paper presented at the IUTAM Symposium on Swelling and Shrinking of Porous Materials: From Colloid Science to Poromechanics - August 06-10 2007, LNCC/MCT. Correspondence to: H. Christopher Greenwell E-mail: chris.greenwell@durham.ac.uk shales) encountered during the drilling process. Clay swelling has a tremendously adverse impact on drilling operations. The large increase in bulk volume occurring from clay swelling hinders the removal of cuttings from the drill bit, increases friction between the bit and the borehole, and inhibits formation of the thin filter cake that is necessary to seal the formations consequently leading to unstable boreholes, sometimes resulting in sheared or damaged drill bits, which dramatically slows drilling and significantly increases exploration and production costs. Various figures have been estimated for losses due to borehole instability, generally these are in the region of \$500M per annum (Bloys et al. 1994, Boek et al. 1995). 
The development of effective clay swelling inhibitors is an important goal of the oil and gas exploration industry.

Owing to the disordered nature of clay minerals, and the variability of natural clay composition, laboratory based analysis and characterization of the action of swelling inhibitors in these minerals is highly challenging. It is difficult, if not impossible, to experimentally replicate the interaction of swelling inhibitors with clay minerals under borehole conditions. With recent advances in computational hardware, and the development of increasingly efficient algorithms, computer simulation has become an extremely useful, if not essential tool for understanding the underlying principals behind clay swelling (Bougeard and Smirnov 2007) and for determining how clay swelling inhibitor molecules interact with clay minerals (Bains et al. 2001).

This present paper highlights the effectiveness of molecular dynamics (MD) simulation techniques in the design of improved swelling inhibitors for use in waterbased drilling fluids (WBDFs). We report on results from some recent large-scale MD simulation studies (Greenwell et al. 2005, 2006b), in which the structure and interactions of low molecular weight, water-soluble poly(propylene oxide)-diamine (PPO-DiAm), poly(ethylene glycol) (PEG) and poly(ethylene oxide)-diacrylate (PEO-DiAc) inhibitor molecules with montmorillonite (Mmt) clays are considered.

In the next sections of this article we introduce the structure of clay minerals, the mechanisms of clay swelling and briefly consider the evolution of technical drilling fluids. We then survey the literature assessing the environmental impact of drilling operations in the marine environment and some of the legislation affecting drilling fluid design. The concepts of MD simulations are briefly reviewed followed by the application of these techniques to study the three different swelling inhibitor polymers described above.

\section{Clay Mineral Structure}

Clay minerals are layered aluminosilicates consisting of stacks of negatively charged two-dimensional layers. Each layer comprises fused sheets of octahedra of $\mathrm{Al}^{3+}$ oxides and tetrahedra of $\mathrm{Si}^{4+}$ oxides (Wyckoff 1968). These silica tetrahedra and aluminium octahedra can be arranged in a variety of different ways in clay sheets. Iso- morphic substitutions of the atoms in the tetrahedral and octahedral sites, e.g., $\mathrm{Si}^{4+}$ by $\mathrm{Al}^{3+}$ and $\mathrm{Al}^{3+}$ by $\mathrm{Mg}^{2+}$, can lead to an overall negative charge on the clay layers. This is balanced by sorption of charge-balancing cations into the interlayer, and on surfaces and edges of the clay sheet. The interlayer cations are exchangeable and may be replaced with other cations under appropriate conditions. The cation exchange capacity (CEC) of clay minerals depends upon crystal size, $\mathrm{pH}$ and the type of exchangeable cation (Pinnavaia 1983). In natural clays there is variability in the charge balancing ions, which tend to be small inorganic species such as $\mathrm{Na}^{+}$and $\mathrm{Ca}^{2+}$ cations, the charge distribution and structure.

\section{Clay Swelling AND ITS Inhibition IN OIL AND GAS PRODUCTION}

In the presence of water, interlayer cations have a tendency to hydrate forcing the clay layers apart. This can occur via two different mechanisms. The first of these is crystalline swelling and is known, both experimentally (Mooney et al. 1952) and through simulations (for example Boek et al. 1995 and Hensen and Smit 2002), to occur in a discrete fashion through the stepwise formation of integer-layer or mixtures of integer-layer hydrates. Following this, osmotic swelling may occur in some clay minerals where the concentration of cations present in the interlayer is higher than that in the surrounding water (Norrish 1954). Swelling of this variety leads to substantial increases in the interlayer spacing. The tendency of the sodium smectites, frequently encountered during oil exploration, to swell macroscopically is the principle cause of shale instability.

The type, size and charge of cations present in the interlayer have long been known to greatly impact upon the magnitude of clay swelling (Falconer and Mattson 1933, Lutz 1935, Norrish 1954). Cations with high valences have been shown to be more strongly associated with the surfaces of the clay sheets than low valence cations (Norrish 1954, Young and Smith 2000). They have also been shown to reduce swelling when compared to clays containing lower valence cations (ChávezPáez et al. 2001). In addition larger, weakly hydrating cations such as $\mathrm{K}^{+}$and $\mathrm{Cs}^{+}$, which can replace interlayer $\mathrm{Na}^{+}$cations, have been shown to significantly reduce swelling (Norrish 1954, Boek et al. 1995, Young 
and Smith 2000). Weakly hydrating cations have been shown, through computer simulation, to be reluctant to hydrate fully and act to screen the mutually repelling clay surface more effectively than strongly hydrating cations (Boek et al. 1995). Reduction of clay swelling in oilfield applications has been achieved by this method, however high concentrations of toxic $\mathrm{KCl}$ is required, containing about 1 wt. $\% \mathrm{~K}^{+}$cation, which fail the mysid-shrimp bioassay (O’Brien and Chenevert 1973). Consequently, $\mathrm{K}^{+}$fluids currently find low acceptance for offshore drilling in many waters.

Nevertheless, $\mathrm{KCl}$ was commonly used in association with partially-hydrolyzed polyacrylamide (PHPA) as a swelling inhibitor additive in WBDFs throughout the 1960s (Bloys et al. 1994) and its use continues to this day. PHPA helps stabilize reactive shale deposits by coating them with a protective layer of polymer. In the 1970s, the drilling industry switched their attention from WBDFs to the development of oil based drilling fluids (OBDFs) as a means of controlling reactive shales. These fluids proved to be very effective as they had excellent lubricating properties, temperature stability and resulted in minimal swelling. However, the use of OBDFs carries a high environmental price. Even with carefully selected low-toxicity mineral oils, the disposal of treated cuttings still produce a lasting negative environmental impact (Davies et al. 1984). As a consequence, the design and development of environmentally acceptable, biodegradable, WBDFs with OBDF swelling inhibitor properties is currently an area of great interest.

To this end, PEG type polymers have been used in WBDFs to prevent swelling enhancing clay shale stability (Bloys et al. 1994). A relatively low concentration of PEG is required, thus making them relatively cheap to use; and at sufficiently low concentrations they do not significantly affect other important drilling fluid properties such as viscosity and fluid-loss control. High molecular weight $\left(\mathrm{M}_{\mathrm{W}}\right)$ PEGs also reduce the amount of solids dispersion (non-swelling clays particles) that can occur. Moreover PEGs have a relatively low toxicity, though have a long persistence in the environment. It is thought that PEGs work by three main methods to restrict swelling: i) they diffuse into and displace water molecules from the interlayer. This is thought to be driven through the increased entropy of the resul- tant systems, with the collective non-constrained water molecules having higher degrees of freedom than the polymer replacing them; ii) enthalpic terms, with the energy of the clay-inhibitor interaction driving the reaction. Recent work (Chen and Evans 2005) has suggested this may in-fact be more important than the entropic contributions; iii) At a macroscopic level, clay swelling inhibition by high $\mathrm{M}_{\mathrm{w}}$ PEG polymers has been attributed to osmotic dewatering of the clay system. However, Smalley in his recent book (Smalley 2006) suggests a bridging flocculation model is far more likely on the basis of neutron scattering data. This is also confirmed by data by Chen and Evans (2004) showing that the $d$-spacing of clay-PEG systems is irrespective of the $\mathrm{M}_{\mathrm{w}}$ of the PEG used.

To improve the efficiency of clay swelling inhibition, Coveney and co-workers devised an in situ polymerisation, within the reactive shale, of small soluble molecules with reactive end groups (Stackhouse et al. 2001, Coveney et al. 2004). An example of such a system is the PEO-DiAc system reported here (Greenwell et al. 2006a). In these systems it is important to know how the reactive acrylate groups align between the clay sheets. Computer simulation gives molecular insight that is experimentally unavailable.

There have been several simulation studies of the interlayer behaviour and arrangement of quaternary alkyl ammonium species within clay minerals. Zeng and co-workers (Zeng et al. 2003, 2004) have shown that, depending on the alkyl ammonium species used, a range of interlayer arrangements including monolayers, bilayers, pseudo-trilayers, and pseudo-quadrilayers of inhibitor molecules may be observed. Pospísil and co-workers (Pospísil et al. 2001) examined the different intercalation behaviour of ammonium surfactants in Mmt paying particular attention to the host-guest interaction energies. Heinz and co-workers (Heinz et al. 2003, Heinz and Suter 2004) have also examined the structural transitions in organo-ammonium clays where the ammonium has long alkyl chains, comparing simulation results with experimental measurements.

A further approach to swelling control, which has received much attention from the experimental chemistry group of Lin and co-workers (Lin et al. 2001, Chou et al. 2003, 2004, Lin and Chen 2004), is to use 
a water-soluble PPO oligomer terminated with an amine group at each end. It is thought that these amine groups become protonated in the clay interlayer, and as organic hydrophobic cations replace the hydratable metal cations, thus prevent swelling. We have previously studied di-amine systems in a combined experimental and simulation study to understand the effect of organic cation substitution on the structure of the clay interlayer (Greenwell et al. 2005).

Recently, interest has increased in the development of improved and increasingly environmentally friendly swelling inhibition additives for WBDFs based upon a variety of polymers incorporating amine and quaternary alkyl ammonium species (for example, Patel et al. 2007, Kippie and Gatlin 2007, Patel and Stamatakis 2007).

\section{IMPACT OF DRILLING FLUIDS ON THE MARINE} ENVIRONMENT

Increasing environmental concerns and changes in legislation has limited the use of some drilling fluids with known environmental impacts (Geehan et al. 1990), however knowledge of the impact of many types of drilling fluids is still limited. A recent study (Holdway 2002) assessed the acute and chronic toxic effects of drilling fluids on temperate and tropical marine ecological processes, through evaluation of prior laboratory and field studies. Detrimental effects were indicated on a wide variety of ecosystems including pelagic communities, benthic communities, plankton communities, coral reefs, mangroves and seagrass beds. The environmental response close to a contamination source was identified as a toxic or smothering effect, causing species populations and biodiversity decline, or an enrichment effect in which species abundance increased.

Earlier literature recounts the sublethal effects of chromium or ferrochromium lignosulphate based drilling fluids on 35 species of marine organisms (Hinwood et al. 1994). Close to the contamination source, sublethal effects of ester-based drilling fluids are of moderate concern, indicated by the relatively low toxicity measured in the burrowing marine sand snail, Polinices conicus (Gulec 1994). Marine microbial processes are also adversely affected, with changes in substrate specificity of heterotrophic bacteria, as indicated by studies on subgroups including lipolytic and cellulolytic bac- teria (Okpokwasili and Nnubia 1995). Recent studies have found that whilst dissolved contaminants are expected to dilute in seawater to non-harmful levels, potentially toxic contaminants may accumulate through flocculation, potentially resulting in rapid transport of waste material to the seafloor at levels that can impact benthic organisms (Cranford et al. 1999). The benthic boundary layer has characteristics that differ from the overlying water column that may allow particles from drilling fluids to remain in concentrated suspension close to the seabed (Muschenheim and Milligan 1996). Concentrations of barite as low as $0.5 \mathrm{mg} / 1$ (ppm) caused significant effects limiting adult scallop growth of Placopecten magellanicus in the North Atlantic Ocean (Gordan et al. 1992). Studies also indicated that oil droplets sequester contaminating particles, thus affecting levels of contaminants at both the seabed and the surface microlayer (Cranford et al. 1999).

Gray et al. (1990) indicated increased abundance patterns of some species and altered presence and absence of rare species due to barium, hydrocarbons and drilling fluids up to $3 \mathrm{~km}$ from drilling sites, indicating impacts at a distance from platforms not previously considered. Daan et al. (1990, 1994, 1995, 1996) indicates significant effects of OBDFs and ester based drilling fluids (EBDFs) on macrobenthos species abundance up to $1 \mathrm{~km}$ from the drilling site, with the greatest effects shown in the echinoderm Echinocardium cordatum and its symbiont, Montacuta ferruginosa. WBDFs commonly indicated a lack of significant environmental effect in comparison to OBDFs and EBDFs for most species. However, whilst the abundance of most of the indicator species was reduced near OBDFs and EBDFs sources, the abundance of the opportunistic polycheate Capitella capitata was shown to increase indicating organic enrichment owing to changes in sediment properties. Larval settlement of red abalone, Haliotis rufescens, in addition to adult mortality, tissue loss and viability of brown cup coral, Paracyathus stearnsii, were shown to be adversely affected by even low toxicity WBDFs of 0.002-200 mg/l (Raimondi et al. 1997). In addition, whilst components of WBDFs and EBDFs are not considered particularly toxic, they can have a low biodegradability and therefore may persist for long times in the environment. Few studies take into account 
the increased toxicity of bioaccumulation and food chain transfer and its consequential effects at higher trophic levels (Neff et al. 1989, Frost et al. 2002).

In summary, there is a paucity of data on both the acute and chronic effects of drilling fluids and their associated wastes on many marine organisms and ecological processes. Whilst the impacts of drilling fluids on multiple ecological processes have been highlighted, the inherent variation in different natural environments coupled with variations in temporal and spatial scales have so far impeded the ability to predict the long-term impacts of drilling fluids on the marine environment (Holdway 2002). Design of suitable drilling fluid additives can lead to low environmental impact, waste minimization through recycling, and reuse of fluids and their components.

\section{COMPUTER SIMULATION FOR STUDYING CLAY-ORGANIC SYSTEMS}

In many papers concerning polymer-clay systems, the only form of analyses presented are powder X-ray diffraction (PXRD) and, to a lesser extent, thermo-gravimetric analysis (TGA), which reveal the interlayer spacing and organic/water content respectively. Fourier transform infra-red spectroscopy (FTIR) has also been used to study the adsorption of low $\mathrm{M}_{\mathrm{w}}$ amines by clays, for example to demonstrate the presence of Brønsted acid sites in the clay interlayer (Yariv and Cross 2002). These conventional analytical techniques, whilst useful, are by themselves incapable of elucidating the interlayer arrangement, let alone dynamical behaviour. However, the insight gained by these methods provides useful starting data for building models for computer simulation. Computer simulation is a valuable tool for gaining understanding of the arrangement and dynamics of intercalated molecules in clay systems (Greenwell et al. 2006b). The complexity and size of inhibitor-clay systems generally rules out the use of quantum mechanical (QM) based methods other than to understand the interactions between reactive groups and small components and clay sheets. Therefore, simulations are typically carried out using classical force-field based methods. Here interactions between all of the component parts of the system are based upon combinations of empirical force-field terms, which describe bond vibrations, an- gles, torsions, non-bonded van der Waals and coulombic interactions.

\section{Molecular Dynamics}

By applying initial velocities to a configuration of atoms and solving Newton's equations of motion the potential energy surface of a system may be traversed in a deterministic fashion and the temporal evolution of a system followed. This is known as molecular dynamics (MD). In this technique thermal energy is included using a thermostat, which allows potential energy barriers to be overcome, in a realistic manner. The main advantage of the method is that the dynamical evolution of a system, with time, may be followed, which allows comparison with additional experimental techniques such as NMR and quasi-elastic neutron scattering. The data from these simulations provides precise information regarding the coordinates of all atoms within the model at any point in time during the simulation period. This allows the interlayer arrangement and dynamics of organic and water molecules to be evaluated with equal precision.

\section{Modelling Periodic Systems}

In order to model the bulk structure of materials (greater than $10^{23}$ atoms) using relatively small models (generally less than $10^{4}$ atoms), two methods are often employed: (i) The use of super-cells, where the original unit-cell, usually derived from a crystal structure, is replicated several times and then redefined as one larger simulation cell, (ii) periodic boundary conditions are applied to the simulation cell, where the super-cell is considered to be replicated infinitely in all three orthogonal space directions. It is assumed that such an approach will replicate the properties of the extended condensed phase system.

\section{SIMULATION METHODOLOGY}

Each of the model inhibitor-clay systems was prepared as described in our previous work in this area (Boulet et al. 2003, Greenwell et al. 2005, Thyveetil et al. 2008). In this section we briefly recount some of the main simulation details. 


\section{Model Details}

The model clay used was a Wyoming-like Mmt with chemical formula $\left[\mathrm{Al}_{15} \mathrm{Mg}_{2}\right]\left[\mathrm{Si}_{32} \mathrm{O}_{96} \mathrm{H}_{16}\right] \mathrm{M}^{+}\left(\mathrm{M}^{+}=\mathrm{Na}^{+}\right.$, $\left.\mathrm{K}^{+}\right)$. Four possible scenarios of PPO-DiAm $\left(\mathrm{M}_{\mathrm{w}}=\right.$ $248 \mathrm{~g} \mathrm{~mol}^{-1}$, see Fig. 1a) $\mathrm{Na}^{+}-\mathrm{Mmt}$ systems using experimental loadings of inhibitor and water have been simulated: (i) None of the $\mathrm{Na}^{+}$was exchanged and all the amine was unprotonated $\left(-\mathrm{NH}_{2}\right)$; (ii) $33 \%$ of the $\left(-\mathrm{NH}_{2}\right)$ and $\mathrm{Na}^{+}$was exchanged by ammonium species $\left(-\mathrm{NH}_{3}^{+}\right)$; (iii) $66 \%$ of the $\mathrm{Na}^{+}$was exchanged by ammonium species; (iv) all the monomer was protonated ammonium $\left(-\mathrm{NH}_{3}^{+}\right)$, equivalent to exchange of $83 \%$ of the $\mathrm{Na}^{+}$cations. The number of inhibitor intercalants and water molecules remained constant for each model, based upon experimental TGA data (Greenwell et al. 2005) for the PPO- $\mathrm{NH}_{2}$ system and corresponded to $10 \%$ mass inhibitor content and $1 \%$ mass water. The super-cell composition of each model is given in Table I. To investigate finite-size effects, one of the initial models was further replicated to form a super-cell containing 350840 atoms. This was simulated for $0.5 \mathrm{~ns}$.

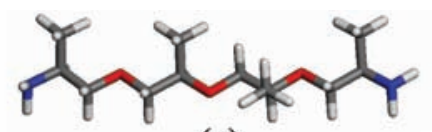

(a)

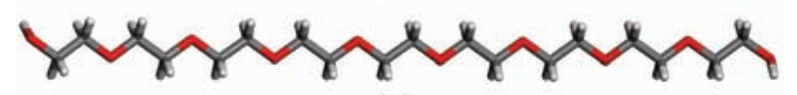

(b)

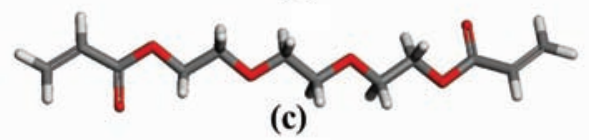

Fig. 1 - Structure of (a) poly(propylene oxide) diamine $\left(\mathrm{PPO}-\mathrm{NH}_{2}\right)$, molecular weight $\mathrm{M}_{\mathrm{W}}=248 \mathrm{~g} \mathrm{~mol}^{-1}$, (b) poly(ethylene glycol) (PEG), $\mathrm{M}_{\mathrm{W}}=414 \mathrm{~g} \mathrm{~mol}^{-1}$ and (c) poly(ethylene oxide) diacrylate $\mathrm{M}_{\mathrm{W}}=$ $258 \mathrm{~g} \mathrm{~mol}^{-1}$ as used in the simulations presented in this work.

A total of four Mmt based systems were simulated consisting of PEG $\left(\mathrm{M}_{\mathrm{W}}=414 \mathrm{~g} \mathrm{~mol}^{-1}\right.$, see Fig. $\left.1 \mathrm{~b}\right)$ and PEO-DiAc $\left(\mathrm{M}_{\mathrm{w}}=258 \mathrm{~g} \mathrm{~mol}^{-1}\right.$, see Fig. 1c), intercalated within $\mathrm{Na}^{+}$and $\mathrm{K}^{+} \mathrm{Mmt}$ galleries. In these simulations models were constructed in the order of 20,000 atoms. The unit cell composition of each model is given in Table I. In order to measure the materials properties of these inhibitor-clay systems, very large-scale simulations are needed to sample the long wavelength undulations required to extract the bending modulus. The undulations are only noticeable for large system sizes; for Mmt, the collective motion of the clay atoms only manifests as long-range undulations at length scales greater than $100 \AA$. We have therefore constructed two very largescale Mmt models through replication of much smaller unit cells: i) intercalated with a double layer of water, with a system size of 1055000 atoms, ii) intercalated with a double layer of PEG $\left(\mathrm{M}_{\mathrm{w}}=3978 \mathrm{~g} \mathrm{~mol}^{-1}\right)$ with a system size of 1756020 atoms.

\section{Simulation Code and Parameter Details}

The MD simulations were performed using the Largescale Atomic/Molecular Massively Parallel Simulator, LAMMPS (Plimpton 1995). LAMMPS uses algorithms and techniques that allow the code to exhibit a near linear relationship (scaling) between the number of processors used, or the size of the model system of interest, and the time taken for the simulation to be performed (Hein et al. 2005, Suter et al. 2007). To model the various systems two different parameter sets were required: (i) The Teppen force-field (Teppen et al. 1997), (an extension of the cff91 force-field) which has been specifically parameterized to account for the behaviour of clay minerals, as well as describing the organic molecules was employed to simulate all models $>500000$ atoms in size. This force-field has been validated for the swelling behaviour of the $\mathrm{Na}^{+}-\mathrm{Mmt}$ clays (Hein et al. 2005) and used to study the interlayer arrangement and dynamics of all of the PPO-DiAm-Mmt and PEO-DiAc-Mmt inhibitor-clay systems, as well as the smaller $(<25 \mathrm{~K}$ atoms) PEG-Mmt models (Boulet et al. 2003, Greenwell et al. 2005, 2006a, b). (ii) To calculate the elastic properties of inhibitor-clay systems a completely flexible force-field is required. To this end the more recently developed ClayFF force-field (Cygan et al. 2004) was used to describe the clay framework of the much larger models ( $>1000000$ atoms). This force-field treats most interatomic interactions as non-bonded Coulombic and Lennard-Jones (12-6) pair potentials, which allows complete translational freedom and permits simulation of complex disordered systems. Intercalated organic inhibitor molecules were described by CVFF force-field parameters which are compatible with the ClayFF forcefield. This combination of ClayFF and CVFF has been 
TABLE I

Simulation cell composition of clay-polymer molecular models. For the mixed PPO- $\mathrm{NH}_{2} / \mathrm{NH}_{3}^{+}$systems the percentage $\mathrm{NH}_{3}^{+}$content is labelled.

\begin{tabular}{|c|c|c|c|c|c|c|}
\hline \multirow{2}{*}{ Polymer } & \multirow{2}{*}{$\mathrm{M}^{+}$} & \multirow{2}{*}{ No. Water } & \multicolumn{2}{|c|}{$\%$ Weight } & \multirow{2}{*}{ Time (ns) } & \multirow{2}{*}{ No. Atoms } \\
\hline & & & Water & Polymer & & \\
\hline $\mathrm{PPO}-\mathrm{NH}_{2}$ & $\mathrm{Na}^{+}$ & 56 & 1 & 10 & 1.8 & 7160 \\
\hline $\mathrm{PPO}-\mathrm{NH}_{2} / \mathrm{NH}_{3}^{+}(33 \%)$ & $\mathrm{Na}^{+}$ & 56 & 1 & 10 & 1.0 & 7160 \\
\hline $\mathrm{PPO}-\mathrm{NH}_{2} / \mathrm{NH}_{3}^{+}(66 \%)$ & $\mathrm{Na}^{+}$ & 56 & 1 & 10 & 1.0 & 7160 \\
\hline $\mathrm{PPO}-\mathrm{NH}_{3}^{+}$ & $\mathrm{Na}^{+}$ & 56 & 1 & 10 & 1.0 & 7160 \\
\hline $\mathrm{PPO}-\mathrm{NH}_{3}^{+}$ & $\mathrm{Na}^{+}$ & 56 & 1 & 10 & 0.5 & 350840 \\
\hline PEG & $\mathrm{Na}^{+}$ & 474 & 2.9 & 19.8 & 1.0 & 17784 \\
\hline PEG & $\mathrm{Na}^{+}$ & 0 & 0 & 22.5 & 1.5 & 1756020 \\
\hline PEG & $\mathrm{K}^{+}$ & 705 & 3.6 & 27.4 & 1.0 & 23775 \\
\hline PEO-DiAc & $\mathrm{Na}^{+}$ & 200 & 1.2 & 17.8 & 1.0 & 20840 \\
\hline PEO-DiAc & $\mathrm{K}^{+}$ & 60 & 0.4 & 17.7 & 1.0 & 20420 \\
\hline N/A & $\mathrm{Na}^{+}$ & 720000 & 8.9 & 0 & 4.3 & 1055000 \\
\hline
\end{tabular}

successfully used to describe the intercalation of organolayered double hydroxides (Padma Kumar et al. 2006) and alkylammonium-intercalated smectites (Liu 2007).

In all cases water was represented by the SPC model (Berendsen et al. 1981) which is consistent with the ClayFF, CVFF and Teppen force-fields. Short-range non-bonded interactions were described using a Lennard-Jones 9-6 potential where the Teppen force-field was used and a 12-6 Lennard-Jones potential for the larger systems simulated using the ClayFF and CVFF force-fields. In both cases these interactions were assigned a cut-off distance of $10 \AA$. Calculation of the computationally demanding long range interactions was carried out using the PPPM algorithm (Hockney and Eastwood 1981, Luty et al. 1994, Toukmaji and Board 1996). The rRESPA algorithm was employed to economize simulation time, with an outer time step for electrostatics of $4 \mathrm{fs}$ and an inner time step for bond terms of 0.5 fs. Three-dimensional periodic boundary conditions were applied to all models to represent the bulk material. Models were constrained to be orthogonal by the limits of the LAMMPS package. The inhibitor-clay structures were optimized to remove repulsive interactions and then simulated at $300 \mathrm{~K}$ and $1 \mathrm{~atm}$ using an isobaric-isothermal (NPT) ensemble in which the temperature was controlled via a Langevin thermostat.

\section{Computational Details}

Simulations of the inhibitor-clay systems were performed on a variety of high-end computing resources. In typical recent simulations, a federation of three supercomputing grids was employed to perform the simulations as well as to visualize the data produced; since this is a somewhat novel computing infrastructure we also briefly describe pertinent aspects of it in this section. Simulations were performed on the following federated grid infrastructures: the UK's National Grid Service (www.ngs.ac.uk), including HPCx (www.hpcx.ac.uk), the TeraGrid (www.teragrid.org) and the EU Distributed European Infrastructure for Supercomputing Applications (www.deisa.org). Submission of jobs was facilitated by the Application Hosting Environment (AHE) (http://www.omii.ac.uk/). The AHE allows the submission of geographically distributed jobs through a single uniform interface which interoperates between Globus and Unicore grids and also retrieves output data automatically once a simulation has finished (Coveney et al. 2007a, b).

\section{ANALYSIS AND VisUALIZATION}

Analysis of the potential energy of each simulation showed that all of the model systems were equilibrated within the first $0.2 \mathrm{~ns}$ of simulation and data collection 
was started after this period. Data was collected every $0.1 \mathrm{ps}$ and statistical averages were evaluated over the last $800 \mathrm{ps}$ of simulation where possible. Time averaged radial distribution functions (RDFs) and 1-D atom distribution plots were calculated for selected atom types. Visualization was achieved using the UCSF Chimera package for models containing less than 10,000 atoms. Larger models were visualized using the AtomEye software package (Li 2003), which has more efficient rendering capabilities for larger systems and can be run on parallel processors. Parallel rendering of the trajectories was performed on six processors of an SGI Prism, further reducing time spent on visualization. Fast networks are required in order to transfer data from supercomputing resources for post-processing and visualization. Switched optical networking was used in order to transfer the large quantities of data generated in this study, $\sim 250$ GB. (Coveney et al. 2007b) Specifically, the JANET lightpath research network was utilized (http://www.ja.net/services/lightpath/). This service operates within the UK and connects to similar network infrastructures across Europe and the U.S.

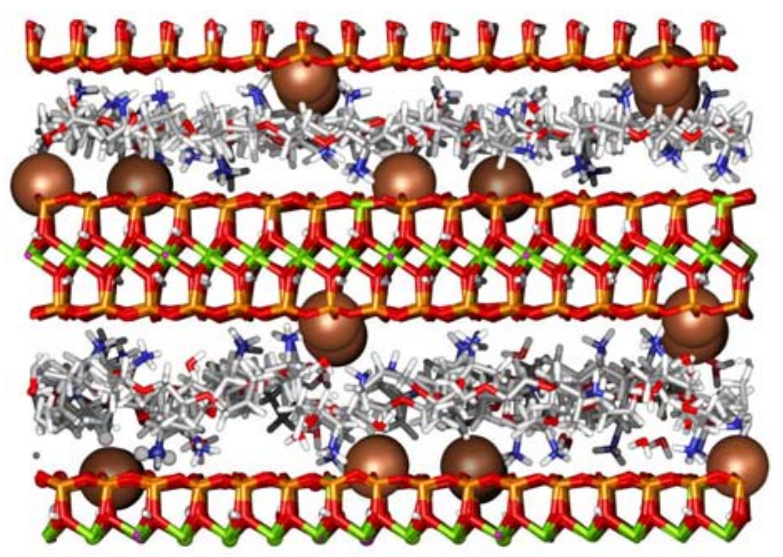

Fig. 2 - Snapshots after 1 ns of molecular dynamics simulation of the 7160 atom $33 \%$ ammonium mix (PPO- $\mathrm{NH}_{2} / \mathrm{PPO}-\mathrm{NH}_{3}^{+}$) system showing the interlayer arrangement of ammonium cations and adjacent clay sheets. The ammonium cation is arranged to maximise $\mathrm{H}$-bond and electrostatic interactions. When compared to the $\mathrm{Na}^{+}$ cation, the ammonium cation is unable to sit closer to the cavities in the tetrahedral layer of the clay sheet due to steric restrictions and strong $\mathrm{H}$-bond interactions with surface siloxane surface $\mathrm{O}$ atoms. The colour scheme is: $\mathrm{C}$ gray, $\mathrm{H}$ white, $\mathrm{O}$ red, $\mathrm{N}$ blue, $\mathrm{Si}$ orange, $\mathrm{Al}$ green, $\mathrm{Na}^{+}$brown.

\section{RESULTS}

In this section we first present the results obtained from our studies of $\mathrm{Na}^{+} \mathrm{Mmt}$ with PPO-DiAm swelling inhibitors, and examine the results of increasing protonation of the amine group. This is followed by the results from studies of PEG swelling inhibitors in $\mathrm{Na}^{+}$ Mmt, the way PEG effects plasticity and other material behaviour of the clay-water-inhibitor system, and then the effect of functionalizing the PEG with DiAc. We next look at the effect of exchanging the $\mathrm{Na}^{+}$cation for $\mathrm{K}^{+}$cations as might be the case where $\mathrm{KCl}$ brines are used to help suppress swelling. By examining the interactions at a molecular level the subtle interactions between inhibitor and clay and effect on water arrangement can be deduced, vital for successful design of drilling fluid composition.

\section{PPO-DIAMINE $\mathrm{NA}^{+}-$MMT SYSTEMS}

\section{Interlayer arrangement and bonding in $\mathrm{PPO}-\mathrm{NH}_{2}$ inhibitor-clay systems}

The PPO- $\mathrm{NH}_{2}$ molecules in the simulated 7160 atom system formed a monolayer with a $d$-spacing of $13.98 \AA$ $( \pm 0.002 \AA)$. This is in good agreement with the experimental value of $14.3 \AA$ (Greenwell et al. 2005). Figure 3 shows the $1 \mathrm{D}$ atom density distribution across the interlayer regions for the amine/ammonium group $\mathrm{N}$ and $\mathrm{H}$ atoms. The $\mathrm{PPO}-\mathrm{NH}_{2} \mathrm{~N}$ atoms are located slightly offset either side of the mid-plane of the interlayer. Little or no H-bonding occurs between the amine groups and the siloxane surface oxygen atoms in the tetrahedral layer of the clay sheet. The other atoms in the PPO backbone are observed to lie along the mid-plane of the interlayer region. The interlayer water molecules in this system are arranged almost parallel with the clay sheets. The water $\mathrm{O}$ atoms are arranged near the interlayer midplane, but oriented towards the face of the clay sheets with the water $\mathrm{H}$ atoms residing close to, but slightly offset from, the mid-plane of the interlayer. As in all the systems we have investigated, $\mathrm{Na}^{+}$cations were arranged mainly adjacent to the face of the clay sheet, sometimes penetrating into the tetrahedral layer slightly. The RDF for this system showed that the $\mathrm{Na}^{+}$cations are closely

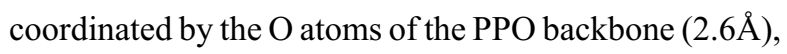
the interlayer water $(2.4 \AA)$, the clay sheet $(2.6 \AA)$, and by 
(a)

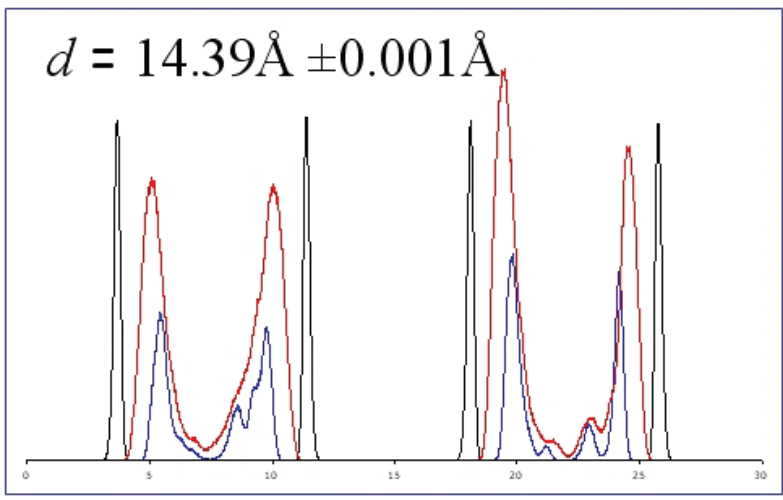

(c)

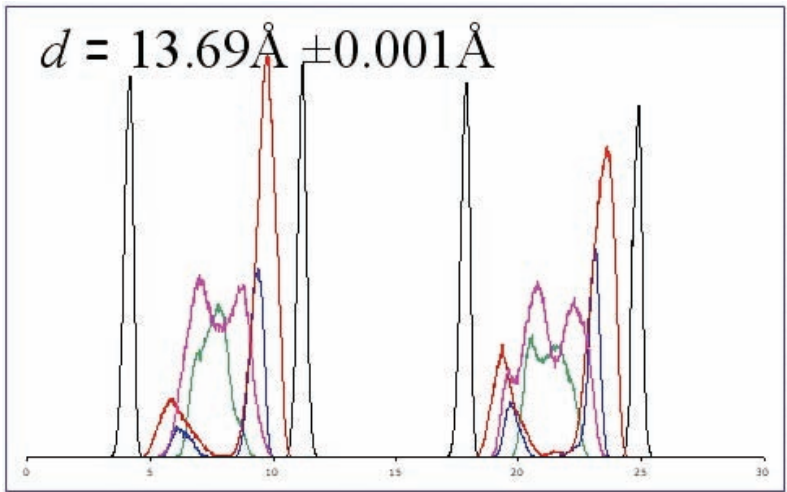

(b)

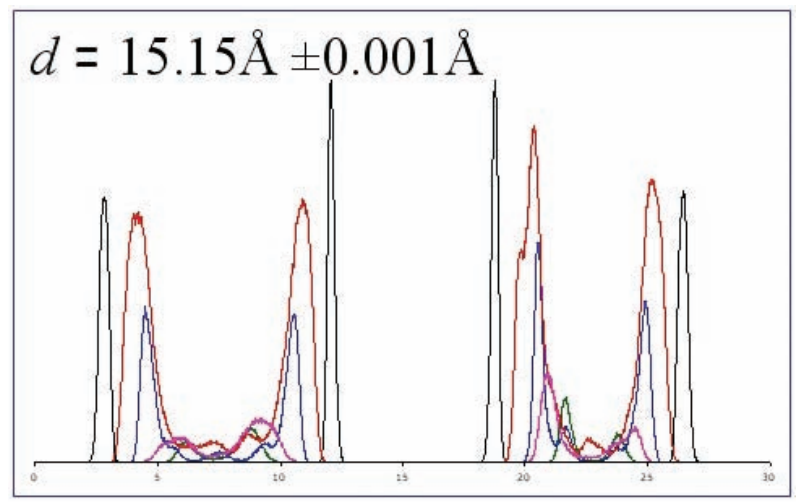

(d)

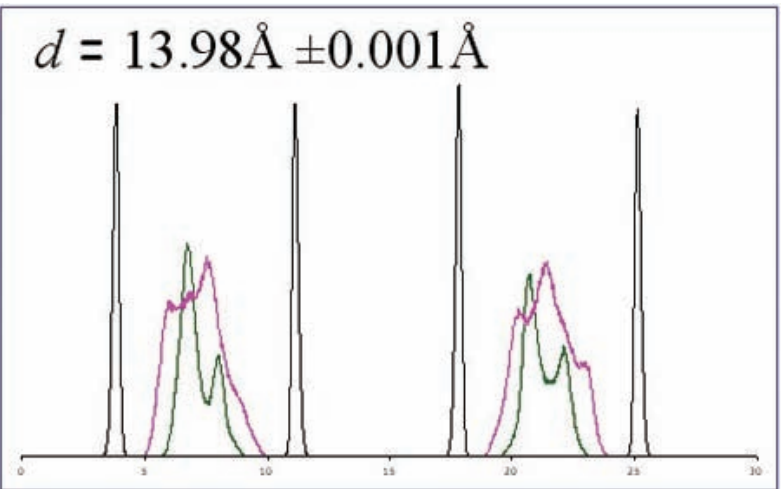

Fig. 3 - One-dimensional atom density maps for interlayer species in MD simulations of, (a) poly(propylene oxide) diammonium (PPO$\mathrm{NH}_{3}^{+}$); (b) poly(propylene oxide) $66 \%$ mix ( $\mathrm{PPO}-\mathrm{NH}_{2} / \mathrm{PPO}-\mathrm{NH}_{3}^{+}$); (c) poly(propylene oxide) $33 \%$ mix (PPO-NH $2 / \mathrm{PPO}^{-} \mathrm{NH}_{3}^{+}$) composites; (d) poly(propylene oxide) diamine ( $\left.\mathrm{PPO}-\mathrm{NH}_{2}\right) \mathrm{Na}^{+}$-montmorillonite. Colours are as follows: Siloxane surface clay O atoms (black), ammonium $\mathrm{N}$ (blue), amine $\mathrm{N}$ (green), ammonium $\mathrm{H}$ (red), amine $\mathrm{H}$ (pink).

the $\mathrm{N}$ atoms of the amine groups $(2.5 \AA)$. A PPO-aminosodium cation coordination has also been postulated by Lin et al. (2004), who suggested that the combined O and $\mathrm{N}$ atom coordination to $\mathrm{Na}^{+}$provides a driving force for adsorption of the organic molecules.

\section{Interlayer arrangement and bonding in $\mathrm{PPO}-\mathrm{NH}_{3}^{+}$} inhibitor-clay systems

The simulated $d$-spacing for the 7160 atom system ammonium system was $14.39 \AA$ (with a standard deviation of $\pm 0.001 \AA$ ), in reasonable agreement with the experimental work of both ourselves (Greenwell et al. 2005) and others (Lin and Chen 2004), but approximately $0.5 \AA$ more than for the simulated PPO- $\mathrm{NH}_{2}$ system. The difference can be rationalized by considering the atom distribution within the interlayer (Fig. 3) and comparing it to the distribution for the $\mathrm{PPO}-\mathrm{NH}_{2}$ model. Figure $3 \mathrm{a}$ shows the distribution of the ammonium group $\mathrm{N}$ and $\mathrm{H}$ atoms in comparison to the siloxane surface $\mathrm{O}$ atoms of each clay layer. The ammonium groups are predominantly arranged adjacent to the face of the clay sheets, with the ammonium $\mathrm{H}$ atom density closer ( $c a$. $1.5 \AA$ ) to the siloxane surface $\mathrm{O}$ atoms than the ammonium $\mathrm{N}$ atom density ( $c a .1 .9 \AA$ ), indicating the formation of a domain of ammonium groups $\mathrm{H}$-bonded to the aluminosilicate sheets. The slightly expanded interlayer in the PPO- $\mathrm{NH}_{3}^{+}$system arises due to conformational changes in the molecules, discussed below, to allow the positively charged ammonium $\left(-\mathrm{NH}_{3}^{+}\right)$groups to locate adjacent to the negatively charged clay sheets, also increasing H-bonding interactions between the ammo- 
nium $\mathrm{H}$ atoms and the $\mathrm{O}$ atoms of the silicate sheet. This conformational change does not occur when only amine $\left(-\mathrm{NH}_{2}\right)$ groups are present.

The PPO- $\mathrm{NH}_{3}^{+}$backbone $\mathrm{C}$ and $\mathrm{O}$ atoms, Figure $3 \mathrm{~b}$, are arranged along the mid-plane of the interlayer region, with the methyl groups and the $\mathrm{O}$ atoms both slightly offset either side of the mid-plane, due to the staggered nature of these groups in the PPO backbone. The $\mathrm{Na}^{+}$cations adopted positions along the face of the clay sheets (Fig. 3c), in some cases interpenetrating the rings formed by the siloxane surface oxygen atoms of the tetrahedral aluminosilicate layer. In the case of the ammonium-intercalated systems with very few $\mathrm{Na}^{+}$cations the interlayer water adopted an arrangement close to the faces of the clay sheets, with the water $\mathrm{H}$-atoms oriented predominantly closer to the face of the clay sheet than the water $\mathrm{O}$ atoms. This arrangement of water molecules is in contradistinction to the PPO$\mathrm{NH}_{2}$ systems where the water $\mathrm{O}$ atoms were arranged near to the interlayer mid-plane and oriented co-planar with the clay sheets.

A more detailed analysis of the local environment about each atom type is given by the RDFs (not shown). The ammonium cation $\mathrm{H}$ atoms are coordinated strongly by interlayer water (1.8§ inter-nuclear separation), indicating that the ammonium ion behaves somewhat akin to a $\mathrm{Na}^{+}$cation. The ammonium $\mathrm{H}$ atoms also strongly interact with the siloxane surface $\mathrm{O}$ atoms of the clay sheet at a distance of some $2.4 \AA$, as suggested by the 1-D atom distributions. This arrangement of the positively charged ammonium groups is again similar to the similarly charged $\mathrm{Na}^{+}$cations, which also interact closely with the $\mathrm{O}$ atoms in the PPO backbone. The ammonium group is oriented such that the H-bonding and favourable electrostatic interactions are maximized. In conditions of low interlayer water content, $\mathrm{Na}^{+}$cations, by comparison, tend to interpenetrate slightly into cavities within the tetrahedral layer of the clay sheet so as to maintain a full coordination shell of $\mathrm{O}$ atoms made up partly by water, partly by clay.

The large-scale, 350840 atom system, simulated for $0.5 \mathrm{~ns}$, showed an average simulated $d$-spacing of $14.40 \AA$ ( $\pm 0.001 \AA)$. The 1-D atom maps were found to differ slightly from the corresponding smaller model, the distribution of atom types retained the same broad features in both systems, but the atom density in the larger system was found to be less constrained than in the smaller model. Visualization showed that some undulations in the clay layers had formed (see Greenwell et al. 2005). It is likely that this effect is due to the large supercell employed; small periodic models are much more tightly constrained by symmetry to rigid clay sheets. In short, absence of such undulations is due to finite size effects. The observation of such clay sheet undulations are of significance as they allow the calculation of materials properties, vide infra.

\section{Interlayer arrangement and bonding in $\mathrm{PPO}-\mathrm{NH}_{3}^{+} / \mathrm{PPO}-\mathrm{NH}_{2}$ inhibitor-clay systems}

The simulated PPO- $\mathrm{NH}_{3}^{+} / \mathrm{NH}_{2}$ systems had average $d$ spacings of $13.69 \AA( \pm 0.001 \AA)$ and $15.15 \AA( \pm 0.001 \AA)$ for the $33 \%$ ammonium and $66 \%$ ammonium systems respectively. The larger average $d$-spacing for the latter case arises due to one of the interlayers in the model being significantly more expanded ( $c a .15 .9 \AA)$ than the other ( $c a .14 .4 \AA$ ), the reason for which is described in more detail below.

An examination of the atom density distribution across the interlayer shows that the ammonium groups in both PPO- $\mathrm{NH}_{3}^{+} / \mathrm{NH}_{2}$ systems (Fig. 3) behaved similarly to those in the PPO- $\mathrm{NH}_{3}^{+}$system, being found adjacent to the clay sheet siloxane surface $\mathrm{O}$ atoms as can also be seen in Figure 2. In contrast to the PPO$\mathrm{NH}_{2}$ systems, the amine groups in the $66 \%$ ammonium system were further away from the mid-plane of the interlayer, with the bulk of the amine $\mathrm{H}$ atom density located towards the positively charged ammonium groups, suggesting possible H-bonding between these species, which is manifested in the RDF plot discussed later. The amine groups in the $33 \%$ ammonium system were distributed more in line with the amine groups in the PPO-NH${ }_{2}$ system (Fig. 3). The monomer backbone $\mathrm{C}$ and $\mathrm{O}$ atoms were distributed in the mid-plane of the interlayer, with the exception of the much wider interlayer noted above. In this larger interlayer phase, of $d$-spacing ca. $16 \AA$, the PPO appeared to form a bilayer, or pseudo-bilayer, arrangement. The pendant methyl groups formed a pseudo-trilayer and the $\mathrm{O}$ atoms were broadly distributed. Visualization of the monomers 
showed that this was due to intra-molecular H-bonding causing a coiled monomer conformation to arise, resulting in an apparent bilayer arrangement.

The distributions of $\mathrm{Na}^{+}$cations and water across the interlayer are similar to those of the $\mathrm{PPO}-\mathrm{NH}_{3}^{+}$system (Fig. 3) for the $66 \%$ ammonium system, and followed the $\mathrm{PPO}-\mathrm{NH}_{2}$ system for the $33 \%$ ammonium system. This illustrates that the distribution of interlayer $\mathrm{Na}^{+}$and water varies according to the number of amine groups that have been protonated. So far as the intercalated organic molecules are concerned, in scenarios where there are predominantly ammonium groups the interlayer adopts an arrangement similar to the case where there are all ammonium groups, and vice versa for amine groups and compounds. The RDFs for the amine $\mathrm{N}$ atoms (not shown) indicate that the ammonium $\mathrm{H}$ atoms approach within $1.9 \AA$ on average, indicating strong H-bonding. The strong nature of such H-bonding in the simulated system would also be a plausible explanation for the high shift noted for the $\mathrm{N}-\mathrm{H}$ bending mode absorption (indicative of H-bonding) in the PPO- $\mathrm{NH}_{2}$ and PPO- $\mathrm{NH}_{3}^{+} / \mathrm{NH}_{2}$ systems FTIR spectra (Greenwell et al. 2005), suggesting that in the $\mathrm{PPO}-\mathrm{NH}_{2}$ system a mixture of $\mathrm{H}$-bonded $-\mathrm{NH}_{2}$ and $\mathrm{NH}_{3}^{+}$groups exist in the interlayer, rather than just $-\mathrm{NH}_{2}$.

\section{PEG BASED NA ${ }^{+}-$MMT INHIBITORS}

Simulations revealed average $d$-spacings of $1.70 \mathrm{~nm}$ for the $\mathrm{Na}^{+}-\mathrm{Mmt}-\mathrm{PEG}$ system. The 1-D atom density distribution for the $\mathrm{PEO}$ backbone $\mathrm{C}$ atoms shows two distinct peaks corresponding to a definite bilayer arrangement for PEG, concentrated within a relatively narrow region about the mid-plane. In the $1-\mathrm{D}$ atom density distribution plot, the $\mathrm{Na}^{+}$cations are found embedded in the faces of the clay sheets, with a very small number of $\mathrm{Na}^{+}$cations further out into the interlayer region adjacent to the face of the clay sheets (Fig. 4). The water molecules were found to hydrate the exposed surfaces of the $\mathrm{Na}^{+}$cations studding the clay surface and pointing toward the interlayer space. As such the water molecule distribution follows the asymmetry present in the $\mathrm{Na}^{+} 1-\mathrm{D}$ atom density distribution and the formation of hydration spheres is apparent from the $\mathrm{Na}^{+}$/water RDF. Due to the presence of the $\mathrm{Na}^{+}$cations and associated water molecules at the face of the clay sheets, the organic molecules were further from the clay sheet resulting in the more compact bilayer. $\mathrm{Na}^{+}$ions interacted with the PEG hydroxide groups and the PEG backbone $\mathrm{O}$ atoms.

\section{Bulk properties of PEG systems}

Intercalation of polyethers such as PEG can not only affect the swelling properties of clay but can also change the elastic and viscoelastic properties of the clay material. However, experiment measurements of the elastic moduli of smectite clay platelets have, thus far, not been successful (Chen and Evans 2006), so it is not possible to calculate values of modulus to use in composite theory; inhibited clay systems can be considered as high clay fraction clay-polymer composites. To calculate the material properties of Mmt, in Figure 5 we show the spectral intensity per undulatory mode versus wave-vector in the $x$ and $y$ directions for Mmt with water and with $3978 \mathrm{~g} \mathrm{~mol}^{-1}$ PEG polymer, with system sizes of 1055000 and 1756020 atoms respectively (Table I). To calculate the elastic properties of the Mmt sheet, we relate the wavelength and amplitude of the thermal undulations of the clay sheet to its material properties, such as the bending modulus, $k$ (Suter et al. 2007):

$$
h|(q)|^{2}=\frac{k_{B} T}{A k q^{4}},
$$

where $h$ is the height function of the clay sheet, $q$ is the wavevector of the undulation, $A$ is the area of the clay sheet, $k_{B}$ is the Boltzmann constant and $T$ is the temperature.

We find through fitting the long wavelength behaviour to a $q^{-4}$ fit that the bending modulus in both $x$ and $y$ directions to be $1.7 \times 10^{-17} \mathrm{~J}$, for both clay systems. The identical bending moduli indicates that the undulations of the clay are unaffected by the interfacial medium. This is likely to be due to the very large in-plane elastic modulus of the clay sheet, which is far greater than the intercalated medium.

\section{DiAc functionalized PEO inhibitors}

Simulations revealed average $d$-spacings of $1.59 \mathrm{~nm}$ for the $\mathrm{Na}^{+}-\mathrm{Mmt}-\mathrm{PEO}-\mathrm{DiAc}$ systems respectively. The $1-$ $\mathrm{D}$ atom density distribution for the PEO backbone $\mathrm{C}$ 
atoms has two distinct peaks corresponding to a definite bilayer arrangement for the $\mathrm{Na}^{+}-\mathrm{Mmt}-\mathrm{PEO}-\mathrm{DiAc}$. The carbonyl $\mathrm{O}$ atoms on the PEO-DiAc were found, in part, to have a similar spatial distribution to the PEO C atoms, but also occupied much of the space along the mid-plane of the interlayer suggesting cross-linking between the acrylate end groups in different monolayers may be possible. A similar distribution occurred for the PEG hydroxyl groups. The RDFs also show that the $\mathrm{Na}^{+}$ also interacted somewhat with the PEO-DiAc carbonyl $\mathrm{O}$ atoms and the PEO chain $\mathrm{O}$ atoms of the PEO-DiAc.

\section{THE EFFECT OF EXCHANGING NA ${ }^{+}$FOR $\mathrm{K}^{+}$} IN MMt Systems

Simulations revealed average $d$-spacings of $1.69 \mathrm{~nm}$ and $1.84 \mathrm{~nm}$, respectively, for the $\mathrm{K}^{+}-\mathrm{Mmt}-\mathrm{PEO}-\mathrm{DiAc}$ and the $\mathrm{K}^{+}-\mathrm{Mmt}-\mathrm{PEG}$ system. The larger $d$-spacing of the $\mathrm{K}^{+}-\mathrm{Mmt}-\mathrm{PEG}$ was found to correspond to a clear trilayer arrangement of organic molecules (Fig. 4) compared to the bilayer observed for the $\mathrm{K}^{+}-\mathrm{Mmt}-$ PEO-DiAc. In the $\mathrm{K}^{+}-\mathrm{Mmt}-\mathrm{PEO}-\mathrm{DiAc}$ the $\mathrm{K}^{+}$cations were distributed only adjacent to the faces of the clay sheet. This suggests that $\mathrm{K}^{+}$has better mobility within the interlayer, due to lower charge density resulting in lower interaction with water and monomers, and is able to migrate to the face of the clay sheet. For the $\mathrm{K}^{+}-$ Mmt-PEG, a small amount of $\mathrm{K}^{+}$atom density was observed towards the mid-plane of the interlayer (Fig. 4). Analysis of the 1-D atom density distribution plots and RDFs for the water $\mathrm{O}$ atoms, the PEO $\mathrm{C}$ atoms and the PEO-DiAc carbonyl $\mathrm{O}$ atoms showed that the $\mathrm{K}^{+}$cation was approached as closely by the organic molecule as the water molecules, and in fact the carbonyl $\mathrm{O}$ atoms in the PEO-DiAc were closer to the face of the clay sheets than the water $\mathrm{O}$ atoms. The fact that the organic molecule approaches the cation as closely as the water supports the suggestion that the $\mathrm{K}^{+}$cation has less interaction with water due to its lower surface charge density relative to $\mathrm{Na}^{+}$.

\section{DISCUSSION}

In the PPO-DiAm systems, the interlayer spacing under the controlled conditions of computer simulations, for systems that differ only in the number of amine/ammonium groups and $\mathrm{Na}^{+}$cations, was found to be depen- dent on the number of intercalated ammonium groups, and showed good agreement with the experimentally observed monolayers at similar organic and water loadings. Computer simulation shows that the organic molecules studied in this work are generally arranged in a monolayer within the interlayer. The PPO backbones of the molecules are arranged along the mid-planes of the interlayer and the orientation of the headgroups depends on whether an ammonium or amine group is present. The arrangement of the PPO backbone contrasts with the behaviour of PEO based polymers (as can be seen in the following section), which are hydrophilic and arrange themselves along the face of the clay sheets to form bilayers (Boulet et al. 2003).

As discussed, in MD simulations the amphiphilic nature of the $\mathrm{Na}^{+}-\mathrm{Mmt}$ is influenced by the presence of organo-ammonium species, the orientation of water molecules within the interlayer depending upon whether the monomers were terminated with ammonium or amine groups, due to the changes in H-bonding networks and absence of $\mathrm{Na}^{+}$cations which might otherwise coordinate the water strongly.

The range of the calculated $d$-spacings for the $\mathrm{Na}^{+}$systems showed good agreement with experimental values, given the differences in composition and uncertainty in the degree of intercalated material, typically within about $5 \%$. The ability of the $\mathrm{Na}^{+}$cations to diffuse into the tetrahedral pockets of the clay surface has already been observed both experimentally (Yang and Zax 1999) and theoretically (Hackett et al. 2000) for $\mathrm{Li}^{+}$and $\mathrm{Na}^{+}$cations. The absence of the cations and their associated hydration spheres, from the interlayer region, results in both a more organophilic interlayer region and more space for organic molecules for a given $d$-spacing.

The simulated $\mathrm{K}^{+}$-Mmt-PEO-DiAc systems showed particularly poor agreement to experimental $d$-spacing. However, it should be noted that the experimental XRD reflections are very broad for $\mathrm{K}^{+}-\mathrm{Mmt}-\mathrm{PEO}-\mathrm{DiAc}$ systems (Greenwell et al. 2006b). Paradoxically, these systems containing $\mathrm{K}^{+}$cations, which have been shown to be less able to migrate into the tetrahedral layers of the clay sheets, sometimes have very high organic loadings based on TGA data (Greenwell et al. 2006b). This can be accounted for through the experimental observation 
(a)

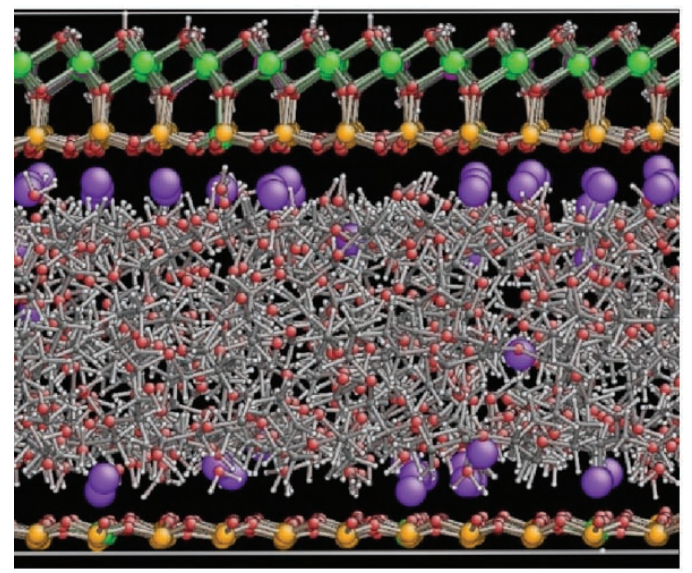

(c)

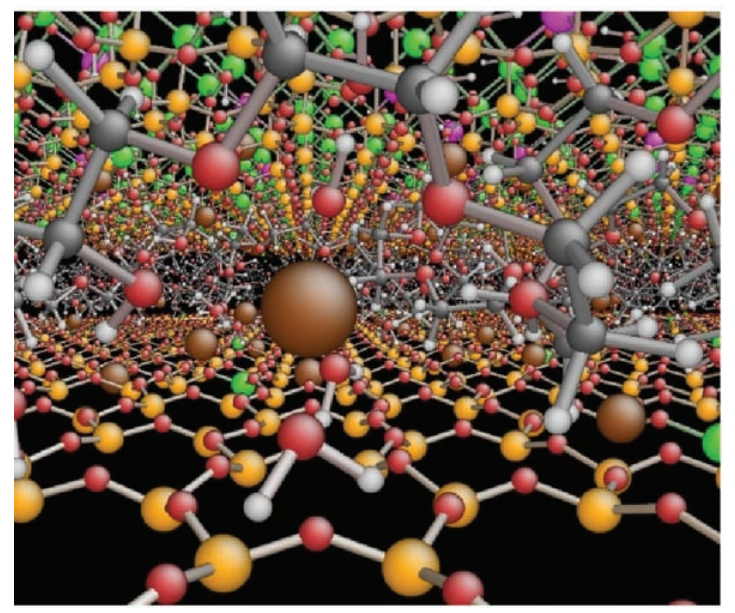

(b)

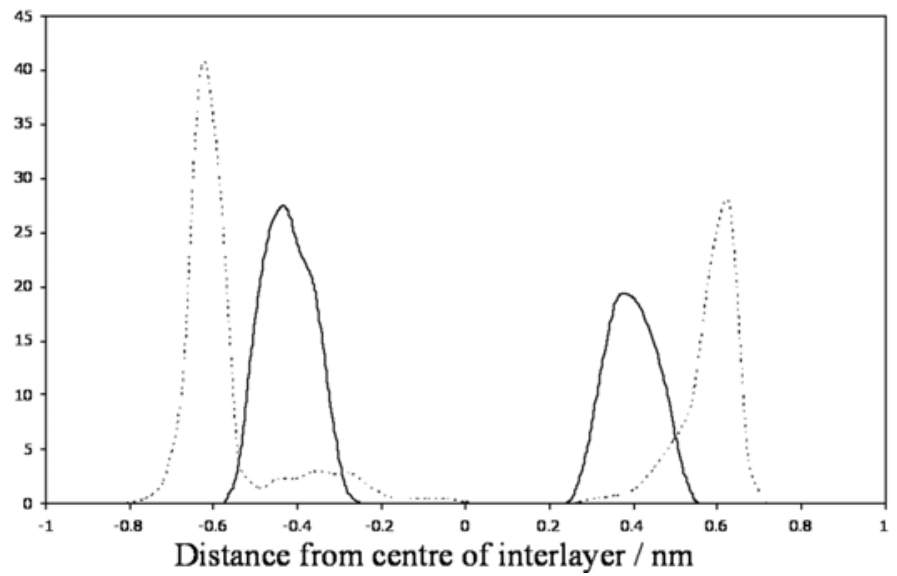

(d)

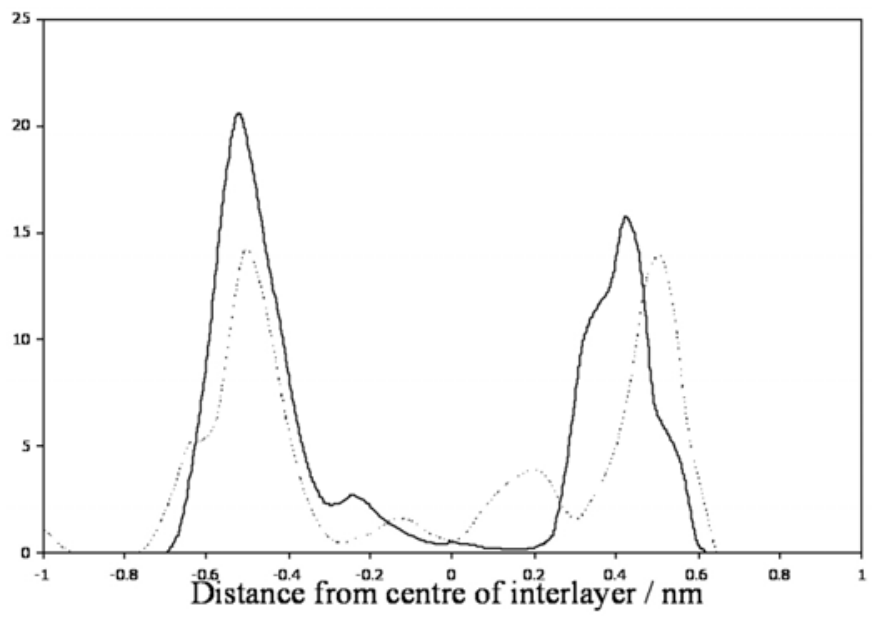

Fig. 4 - Snapshots after $1 \mathrm{~ns}$ of molecular dynamics simulation for (a) the PEG-K ${ }^{+} \mathrm{Mmt}$ composite and (c) the PEG-Na ${ }^{+} \mathrm{Mmt}$ composites. The one-dimensional atom density maps of the change in $\mathrm{K}^{+}$cation distribution for the simulated PEG and PEO-DiAc $\mathrm{K}^{+}$Mmt composites is

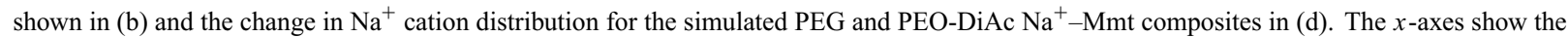
distance from the centre plane of the interlayer in $\mathrm{nm}(\times 10)$. The $y$-axes show the arbitrary density. Dashed line $=$ poly $($ ethylene glycol $)$ and solid line $=$ poly (ethylene oxide) diacrylate for comparison .

that these materials tend to exfoliate and hence exhibit domains where single clay sheets are not assembled in tactoids, but are rather dispersed throughout the polymer matrix. Exfoliation accounts for the lack of agreement between simulated and experimental $d$-spacings for the $\mathrm{K}^{+}-\mathrm{Mmt}$ systems, since exfoliation cannot be simulated in these strictly periodic models. The propensity for $\mathrm{K}^{+}-\mathrm{Mmt}$ to exfoliate is noteworthy as it is in contrast to the known resistance of the $\mathrm{K}^{+}-\mathrm{Mmt}$ to water swelling (Boek et al. 1995) and illustrates the need to understand mineral-organic interactions when designing drilling fluids; the use of $\mathrm{K}^{+}$salt inhibitors with certain organic inhibitors may lead to dispersion and destabilization of clay fractions.

For all the simulated PEG systems no evidence was found for H-bond interactions between the protons of the PEG alcohol groups and the tetrahedral $\mathrm{O}$ atoms of the clay surface. Therefore, it seems that in the presence of water and cations, PEG is unlikely to adsorb strongly at the clay surface. The PEO chains for both PEO-DiAc and PEG tend to orientate with the $\mathrm{O}$ atoms towards the mid-plane for the $\mathrm{Na}^{+}$clays, away from the 
cations which reside at the clay sheet surface. This arrangement, which results in organic monomer $\mathrm{C}$ atoms adjacent to the organophilic silica surface, has been reported previously by others (Bujdak et al. 2000).

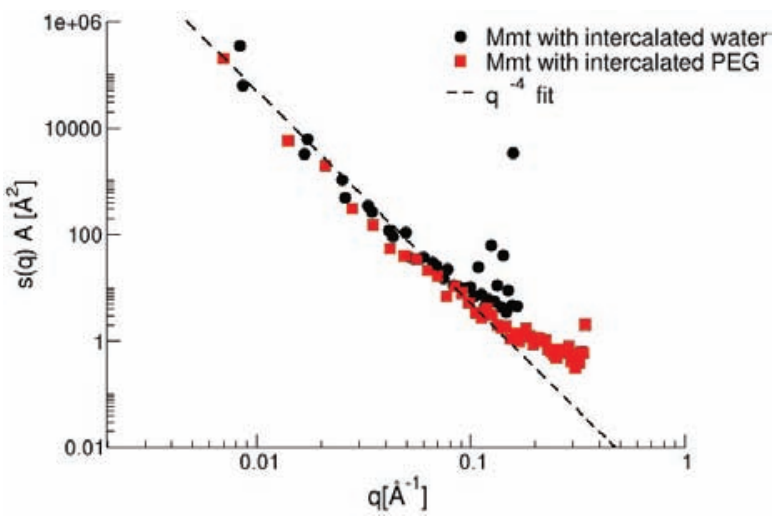

Fig. 5 - Spectral intensity per undulatory mode versus wave-vector in the $x$ and $y$ directions for MMT intercalated with water (1055000 atoms) and $3978 \mathrm{~g} \mathrm{~mol}^{-1}$ PEG (1756020 atoms) in the $x$ and $y$ directions. The dashed line is a fit to the undulatory $q^{-4}$ modes for $q<0.04$ with $k=1.7 \times 10^{-17} \mathrm{~J}$. The local peak centred on $q=0.35 \AA^{-1}$ and $0.175 \AA^{-1}$ is due to artificial periodicity resulting from the way isomorphic substitutions are included in all the models. Isomorphic substitutions in real clays are randomly distributed so this peak can be disregarded.

The choice of functionalized PEO was also found to affect the cation distribution across the system interlayer. In the PEG systems hydroxyl (alcohol -OH) groups retained some of the cations and associated hydrations shells within the interlayer region. The magnitude of this effect is dependent upon the cation, with nearly all the $\mathrm{K}^{+}$migrated to the face of the clay sheet. Since the cations are retained in the interlayer region away from the clay sheet surface they are also closely associated with the monomer backbone $\mathrm{O}$ atoms. Therefore in the RDFs, the order of interaction for both the PEG hydroxyl $\mathrm{O}$ atoms, and the backbone $\mathrm{O}$ atoms, with the cations is: $\mathrm{Na}^{+}>\mathrm{K}^{+}$.

Conversely, the PEO-DiAc, having no alcohol OH groups, did not retain the cations in the mid-plane of the interlayer region; instead, the vast majority of the $\mathrm{Na}^{+}$cations migrate into the tetrahedral layer of the clay sheet, and the $\mathrm{K}^{+}$cations migrate to the face of the clay sheets. Therefore, comparing the RDFs for the inter- action between the different cations and the PEO-DiAc backbone $\mathrm{O}$ atoms, or the endgroup $\mathrm{O}$ atoms, showed the strength of the interaction with the low surface charge density cations decreasing in the order: $\mathrm{K}^{+}>\mathrm{Na}^{+}$.

Furthermore, both the resistance to swelling and the tendency of $\mathrm{K}^{+}-\mathrm{Mmt}$ to exfoliate can be rationalized in light of the fact that the low surface charge density $\mathrm{K}^{+}$cation is not particularly hydrophilic, and sheds its hydration shells (Boek et al. 1995). This both renders the clay more resistant to swelling in an aqueous environment and, if the driving force for intercalation is entropy-favoured displacement of interlayer water, facilitates the uptake of organic molecules, when present, by allowing water of hydration to be exchanged (Bains et al. 2001).

\section{CONCLUSIONS AND FURTHER WORK}

We have reported on the use of large-scale MD on high performance computing facilities, and using grid-computing methods, to undertake simulations of clay swelling inhibitor systems. The results allow interpretation of bulk experimental data of the mode of interaction of swelling inhibitors with clay minerals at an atomistic and molecular level. This highlights the use of computer simulations for the design of new and improved drilling fluids. The ultimate goal of computer aided design is to allow the oilfield industry to produce improved swelling inhibitors for reactive shales that maximize oil and gas recovery and reduce costs associated with wellbore instability. With increasing environmental awareness, the design of biodegradable fluid components, including swelling inhibitors, with similar efficiency to current technologies is a key priority. Furthermore, by using very large-scale simulations, enabled through grid computing, material properties can been calculated for hydrated clay systems, which are in agreement with the experimental data available for related systems. Future work will use the techniques and understanding of swelling inhibitor-clay interactions described here to design, in silico, new swelling inhibitors with improved environmental performance, i.e., increased biodegradability and consequently lower residence time in the ecosystem. 


\section{ACKNOWLEDGMENTS}

The authors would like to thank Prof. Marcio Murad at the LNCC, Petropolis, Brazil and the organizers of the IUTAM symposium. Dr. Greenwell acknowledges the Welsh Assembly Government for a travel grant that enabled his attendance at the symposium. This work was in part supported by the UK Engineering and Physical Sciences Research Council (EPSRC) (GR/T27488/01), which also provided access to HPCx (www.hpcx.ac.uk) and by EPSRC grant Number GR/T04465/01 (ESLEA). We are also indebted to the National Science Foundation for TeraGrid allocations under NRAC Grant MCA04N014 and MRAC Grant DMR070013N, utilizing resources on the U.S. TeraGrid (www.teragrid.org), the UK's National Grid Service (www.ngs.ac.uk) and the DEISA Consortium (co-funded by the EU, FP6 project 508830) within the DEISA Extreme Computing Initiative (www.deisa.org).

\section{RESUMO}

Durante a exploração de óleo e gás um fluido de perfuração é usado para lubrificar 'bit' da perfuradora, manter a pressão hidrostática, transmitir sensores de leitura, remover resíduos da rocha e inibir o inchamento da argila instável baseada nas formações dos folhelhos. O aumento das preocupações ambientais bem como a legislação resultante levou à procura de novos fluidos de perfuração com componentes biodegradáveis. No caso dos aditivos para inibir o inchamento das argilas o entendimento das interações entre os aditivos e as argilas tem que ser adquirido para permitir o projeto de moléculas com melhores propriedades. Devido à natureza desordenada da dimensão nanoscópica dos nano poros dos minerais argilosos, simulações computacionais têm se tornado uma ferramenta poderosa para estudar as interações entre o inchamento da argila e o inibidor. Neste trabalho revisamos brevemente o histórico do desenvolvimento de fluidos técnicos de perfuração, o impacto ambiental dos fluidos de perfuração e o uso de simulações computacionais para estudar as interações entre os fluidos de perfuração e os inibidores do inchamento. Nós reportamos resultados para alguns estudos baseados em simulações de dinâmica molecular em larga escala em uma solução aquosa de baixo peso molecular com solutos compostos por macromoléculas inibidoras. A estrutura e as interações entre inibidores compostos por polipropileno óxido, polietileno óxido e moléculas e a argila montmorilonita são estudadas.
Palavras-chave: inchamento das argilas, fluidos de perfuração, simulações de dinâmica molecular.

\section{REFERENCES}

Bains AS, Boek ES, Coveney PV, Williams SJ AND AKBAR MV. 2001. Molecular modeling of the mechanism of action of organic clay-swelling inhibitors. Mol Simul 26: 101-145.

Berendsen HJC, Postma JPM, van Gunsteren WF AND HERMANS J. 1981. Interaction models for water in relation to protein hydration. In: PULlman B (Ed), Intermolecular Forces. Riedel, Dordrecht, the Netherlands, p. 331-342.

Bloys B, Davis N, Smolen B, Bailey L, Houwen O, Reid P, Sherwood J, Fraser L ANd Hodder M. 1994. Designing and managing drilling fluid. Schlumberger Oilfield Rev 6: 33-43.

Boek ES, Coveney PV And Skipper NT. 1995. Monte Carlo molecular modeling studies of hydrated Li-, Na-, Ksmectites: Understanding the role of potassium as a clay swelling inhibitor. J Am Chem Soc 117: 12608-12617.

Bougeard D AND SMIRnOv KS. 2007. Modeling studies of water in crystalline nanoporous aluminosilicates. Phys Chem Chem Phys 9: 226-245.

Boulet P, Bowden AA, Coveney PV And Whiting AJ. 2003. Combined experimental and theoretical investigations of clay polymer nanocomposites: intercalation of single bifunctional organic compounds in $\mathrm{Na}^{+}$montmorillonite and $\mathrm{Na}^{+}$-hectorite clays for the design of new materials. J Mater Chem 13: 2540-2550.

BuJdAK J, HACKETT E AND GiAnNELis EP. 2000. Effect of layer charge on the intercalation of poly(ethylene oxide) in layered silicates: Implications on nanocomposite polymer electrolytes. Chem Mater 12: 2168-2174.

Chávez-Páez M, van Workum K, de Pablo L and de PABLO JJ. 2001. Monte Carlo simulations of Wyoming sodium montmorillonite hydrates. J Chem Phys 114: 1405-1413.

Chen B And Evans JRG. 2004. Preferential intercalation in polymer-clay nanocomposites. J Phys Chem B 108: 14986-14990.

Chen B And Evans JRG. 2005. On the thermodynamic driving force for polymer intercalation in smectite clays. Phil Mag 85: 1519-1538.

Chen B AND Evans JRG. 2006. Elastic moduli of clay platelets. Scripta Materialia 9: 1581-1585. 
Chou CC, Shieu FS And Lin JJ. 2003. Preparation, organophilicity, and self-assembly of poly(oxypropylene)amine-clay hybrids. Macromolecules 36: 2187-2189.

Chou CC, Chang YC, Chiang ML and Lin JJ. 2004. Conformational change of trifunctional poly(oxypropylene)amines intercalated within a layered silicate confinement. Macromolecules 37: 473-477.

Coveney PV, Watkinson M, Whiting A And Boek ES. 2004. Stabilizing Clayey Formations, US Patent Number 6787507.

Coveney PV, SAKsena RS, Zasada, SJ, McKeown M AND PICKLES S. 2007a. The application hosting environment: Lightweight middleware for grid-based computational science. Comput Phys Commun 176: 406-418.

Coveney PV, Giupponi G, Jha S, Manos S, Suter JL, Thyveetil M-A AND Zasada SJ. 2007b. Large Scale Computational Science on Federated International Grids: The Role of Switched Optical Networks. Preprint.

Cranford P, Armsworthy S, LeE K, Milligan T, Muschenheim K, Hannah C, Loder J, Li M, SonNICHSEN G AND KING E. 1999. Interactions between offshore oil and gas operations and the marine environment. In: PATIN S (Ed), Environmental impact of the offshore oil and gas industry. Ecomonitor Publications.

Cygan RT, Liang JJ And Kalinichev AG. 2004. Molecular models of hydroxide, oxyhydroxide, and clay phases and the development of a general force field. J Chem Phys B 108: 1255-1266.

DAAN R, LEWIS WE AND Mulder M. 1990. Biological effects of discharged oil-contaminated drill cuttings in the North Sea. NIOZRapport 1990-5, Netherlands Institute for Sea Research, North Sea Directorate, Rijswijk, The Netherlands, 79 p.

DaAn RK, Mulder M And LeEwen A. 1994. Differential sensitivity of macrozoobenthic species to discharges of oil-contaminated drill cuttings in the North Sea. Neth J Sea Res 33: 113-127.

DAan R, Booij K, Mulder M ANd VAn WeErleE EM. 1995. A study of the environmental effects of a discharge of drill cuttings contaminated with ester-based drilling muds in the North Sea. NIOZ-Rapport 1995-2, Netherlands Institute for Sea Research, North Sea Directorate, Rijswijk, The Netherlands, $50 \mathrm{p}$.

DaAn R, Booij K, Mulder M and Van Weerlee EM. 1996. Environmental effects of a discharge of drill cuttings contaminated with ester-based drilling muds in the North Sea. Environ Toxicol Chem 15: 1709-1722.
DAVIES JM, AdDY JM, BLACKMAN RA, BLANCHARdS JR, Ferbrache JE, Moore DC, Somerville HJ, WHITEHEAD A AND WILKINSON T. 1984. Environmetal effects of the use of oil-based drilling muds in the north sea. Mar Pollut Bull 15: 363-370.

FALCONER JG AND Mattson S. 1933. The laws of soil colloidal behaviour. XIII. Osmotic inhibition. Soil Sci 36: 317 .

Frost TK, Johnsen S And HJelsvold M. 2002. Environmental risk management of discharges from E\&P activities in the North Sea. Paper for presentation at the SPE International Conference on Health, Safety and Environment in Oil and Gas Exploration and Production held in Kuala Lumpur, Malaysia, p. 20-22.

Geehan T, Helland B, Thorbjornsen K, Maddin C, McIntire B, Shepherd B And Page W. 1990. Reducing the oilfield's environmental footprint. Oilfield Rev 2: $53-63$.

Gordan DC, CRANFord PJ, MUSChEnHEIM DK, LODER JW, KeIZER PD AND KRANCK K. 1992. In: RYAN PM (Ed), Managing the environmental impact of offshore oil Production. In: Proceedings of the $32^{\text {nd }}$ Annual Meeting of the Canadian Society of Environmental Biologists, St. John's, Newfoundland, Canada, p. 139-147.

Gray JS, Clarke KR, Warwick RM and Hobbs G. 1990. Detection of initial effects of pollution on marine benthos: an example from the Ekofisk and Eldfisk oilfields, North Sea. Mar Ecol Prog Ser 66: 285-299.

Greenwell hC, Harvey MJ, Boulet P, Bowden AA, COVENEY PV AND WHITING A. 2005. Interlayer structure and bonding in nonswelling primary amine intercalated clays. Macromolecules 38: 6189-6200.

Greenwell HC, Jones W, Coveney PV And StaCKHOUSE S. 2006a. On the application of computer simulation techniques to anionic and cationic clays: A materials chemistry perspective. J Mater Chem 16: 708-723.

Greenwell hC, Bowden AA, Chen B, Boulet P, Evans JRG, Coveney PV And Whiting A. 2006b. Intercalation and in situ polymerization of poly(alkylene oxide) derivatives within $\mathrm{M}^{+}$-montmorillonite $(\mathrm{M}=\mathrm{Li}$, Na, K). J Mater Chem 16: 1082-1094.

GULEC I. 1994. Evaluation of toxicity of drilling fluids and their impact on marine environment. M.Eng. thesis, University of New South Wales.

Hackett E, Manias E AND Giannelis EP. 2000. Computer simulation studies of PEO/layer silicate nanocomposites. Chem Mater 12: 2161-2167. 
Hein J, Reid F, Smith L, Bush I, Guest M And SherWOOD P. 2005. On the performance of molecular dynamics applications on current high end systems. Phil Trans R Soc A 363: 1987-1998.

HeInZ H AND Suter U. 2004. Atomic charges for classical simulations of polar systems. J Phys Chem B 108: 1834118352.

Heinz H, Castelijns HJ And Suter U. 2003. Structure and phase transitions of alkyl chains on mica. J Am Chem Soc 125: 9500-9510.

Hensen EJM and Smit B. 2002. Why clays swell. J Phys Chem B 106: 12664-12667.

Hinwood JB, Potts AE, Dennis LR, Carey JM, Houridis H, Bell RJ, Thomson JR, Boudreau P AND AYLING AM. 1994. Environmental implications of offshore oil and gas development in Australia - drilling activities. Australian Petroleum Exploration Association (APEA), Energy Research and Development Corporation (ERDC), p. 123-206.

Hockney RW And EASTwood J. 1981. Computer simulation using particles. New York, MacGraw-Hill.

HOLDWAY DA. 2002. The acute and chronic effects of wastes associated with offshore oil and gas production on temperate and tropical marine ecological processes. Mar Pollut Bull 44: 185-203.

Kippie DP AND GatLin LW. 2007. Shale inhibition additive for oil/gas downhole fluids and methods for making and using same. US Patent 7268100.

LI J. 2003. AtomEye: an efficient atomistic configuration viewer. J Modelling Simul Mater Sci Eng 11: 173-177.

LIN JJ AND CHEN YM. 2004. Amphiphilic properties of poly(oxyalkylene)amine-intercalated smectite aluminosilicates. Langmuir 20: 4261-4264.

Lin JJ, Cheng IJ, WANG R And LeE RJ. 2001. Tailoring basal spacings of montmorillonite by poly(oxyalkylene)diamine intercalation. Macromolecules 34: 8832-8834.

LIU X. 2007. Interlayer structure and dynamics of alkylammonium-intercalated Smectites with and without water: A molecular dynamics study. Clay Clay Miner 55: 554-564.

Luty BA, Davies ME, Tironi IG And VAn Gunsteren WF. 1994. A comparison of particle-particle, particlemesh and Ewald methods for calculating electrostatic interactions in periodic molecular systems. Mol Simul 14: 11-20.

LUTZ JF. 1935. The relation of soil erosion to certain inherent soil properties. Soil Sci Soc Am J 40: 439-457.
Mooney RW, KeEnAn AG And Wood LA. 1952. Adsorption of water vapor by montmorillonite. I. Heat of desorption and application of BET theory. J Am Chem Soc 74: 1367-1371.

Muschenheim DK And Milligan TG. 1996. Flocculation and accumulation of fine drilling waste particulates on the Scotian shelf(Canada). Mar Pollut Bull 32: 740-745.

NefF JM, BReteler RJ AND CARR RS. 1989. Bioaccumulation, food chain transfer, and biological effects of barium and chromium from drilling muds by flounder (Pseudopleuronectes americanus) and lobster (Homarus americanus). In: ENGELHARDT FR ET AL. (Eds), Drilling Wastes. Elsevier Science Publishers Ltd, Barking, England, p. 439-460.

NORRISH K. 1954. The swelling of montmorillonite. Discuss Faraday Soc 18: 120-134.

O’Brien DE And Chenevert ME. 1973. Stabilizing sensitive shales with inhibited potassium-based drilling fluids. J Petrol Technol 25: 1089-1100.

OKPOKWASILI GC AND NNUBIA C. 1995. Effects of oil spill dispersants and drilling fluids on substrate specificity of marine bacteria. Waste Manage 15: 515-520.

Padma Kumar P, Kalinichev A And KirkPatrick R. 2006. Hydration, swelling, interlayer structure, and hydrogen bonding in organo layered double hydroxides: Insights from molecular dynamics simulation of citrateintercalated hydrotalcite. J Phys Chem B 110: 38413844.

PATEl AD And Stamatakis E. 2007. Shale hydration inhibition agent and method of use. US Patent 7312183.

Patel AD, Stamatakis E, Davis E And Friedheim J. 2007. High performance water based drilling fluids and method of use. US Patent 7250390.

PinnaVAia TJ. 1983. Intercalated Clay Catalysts. Science 220: $365-371$.

PLIMPTON SJ. 1995. Fast parallel algorithms for short-range molecular dynamics. J Comput Phys 117: 1-19. See also http://lammps.sandia.gov/.

PospíšIl M, ČAPKOVÁ P, MĚŘínSHÁ D, MALÁČ Z AND ŠIMONÍK J. 2001. Structure analysis of montmorillonite intercalated with cetylpyridinium and cetyltrimethylammonium: molecular simulations and XRD analysis. J Colloid Interface Sci 236: 127-131.

RAIMOndi PT, BARnetT AM AND KRAuse PR. 1997. The effects of drilling muds on marine invertebrate larvae and adults. Environ Toxicol Chem 16: 1218-1228. 
SMALley M. 2006. Clay swelling and colloidal stability. CRC Taylor and Francis.

Stackhouse S, Coveney PV And SAndre E. 2001. Plane-wave density functional theoretic study of formation of clay-polymer nanocomposite materials by selfcatalyzed in situ intercalative polymerization. J Am Chem Soc 123: 11764-11774.

Suter JL, Coveney PV, Greenwell HC And ThyVeETIL MA. 2007. Large-scale molecular dynamics study of montmorillonite clay: Emergence of undulatory fluctuations and determination of materials properties. J Phys Chem C 111: 8246-8259.

Teppen BJ, Rasmussen K, Bertsch PM, Miller DM AND SCHÄFER L. 1997. Molecular dynamics modeling of clay minerals. 1. Gibbsite, kaolinite, pyrophyllite, and beidellite. J Phys Chem B 101: 1579-1587.

Thyveetil MA, Coveney PV, Suter J AND GreenWELL HC. 2008. Emergence of undulations and determination of materials properties in large-scale molecular dynamics simulation of layered double hydroxides. Chem Mater 19: 5510-5523.

TOUKMAJI AY AND BOARD JA. 1996. Ewald summation techniques in perspective: A survey. Comput Phys Commun 95: 73-92.
WYCKOFF RWG. 1968. Crystal Structures Vol. 4. New York, London, J Wiley \& Sons.

YANG DK AND ZAX DB. 1999. Li+ dynamics in a polymer nanocomposite: An analysis of dynamic line shapes in nuclear magnetic resonance. J Chem Phys 110: 53255336.

YARIV S AND CROSS H (EDS). 2002. Organo-clay complexes and interactions. New York: Marcel Dekker. Ch. 2.

Young DA AND Smith DE. 2000. Simulations of clay mineral swelling and hydration: Dependence upon interlayer ion size and charge. J Phys Chem B 104: 9163-9170.

ZENG QH, YU AB, LU GQ AND STANDish RK. 2003. Molecular dynamics simulation of organic-inorganic nanocomposites: The layering behaviour and interlayer structure of organoclays. Chem Mater 15: 4732-4738.

ZENG QH, YU AB, LU GQ AND STANDISH RK. 2004. Molecular dynamics simulation of the structural and dynamic properties of dioctadecyldimethyl ammonium in organoclays. J Phys Chem B 108: 10025-10033. 